\title{
Temporal and spatial variability of the stable isotopic composition of atmospheric molecular hydrogen: observations at six EUROHYDROS stations
}

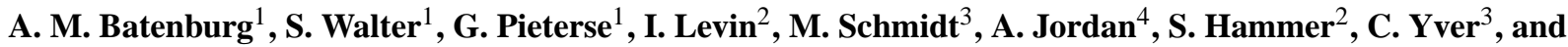 \\ T. Röckmann ${ }^{1}$ \\ ${ }^{1}$ Institute for Marine and Atmospheric Research Utrecht, Utrecht University, Utrecht, The Netherlands \\ ${ }^{2}$ Institut für Umweltphysik, University of Heidelberg, Heidelberg, Germany \\ ${ }^{3}$ Laboratoire des Sciences du Climat et de l'Environnement, Gif sur Yvette, France \\ ${ }^{4}$ Max Planck Institut für Biogeochemie, Jena, Germany
}

Received: 7 March 2011 - Published in Atmos. Chem. Phys. Discuss.: 29 March 2011

Revised: 1 July 2011 - Accepted: 5 July 2011 - Published: 20 July 2011

\begin{abstract}
Despite the potential of isotope measurements to improve our understanding of the global atmospheric molecular hydrogen $\left(\mathrm{H}_{2}\right)$ cycle, few $\mathrm{H}_{2}$ isotope data have been published so far. Now, within the EUROpean network for atmospheric HYDRogen Observations and Studies project (EUROHYDROS), weekly to monthly air samples from six locations in a global sampling network have been analysed for $\mathrm{H}_{2}$ mixing ratio $\left(m\left(\mathrm{H}_{2}\right)\right)$ and the stable isotopic composition of the $\mathrm{H}_{2}\left(\delta\left(\mathrm{D}, \mathrm{H}_{2}\right)\right.$, hereafter referred to as $\left.\delta \mathrm{D}\right)$. The time series thus obtained now cover one to five years for all stations. This is the largest set of ground station observations of $\delta \mathrm{D}$ so far. Annual average $\delta \mathrm{D}$ values are higher at the Southern Hemisphere (SH) than at the Northern Hemisphere $(\mathrm{NH})$ stations; the maximum is observed at Neumayer (Antarctica), and the minimum at the non-arctic NH stations. The maximum seasonal differences in $\delta \mathrm{D}$ range from $\approx 18 \%$ at Neumayer to $\approx 45 \%$ at Schauinsland (Southern Germany); in general, seasonal variability is largest at the $\mathrm{NH}$ stations. The timing of minima and maxima differs per station as well. In Alert (Arctic Canada), the variations in $\delta \mathrm{D}$ and $m\left(\mathrm{H}_{2}\right)$ can be approximated as simple harmonic functions with $a \approx 5$ month relative phase shift. This out-of-phase seasonal behaviour of $\delta \mathrm{D}$ and $m\left(\mathrm{H}_{2}\right)$ can also be detected, but delayed and with a $\approx 6$-month relative phase shift, at Mace Head and Cape Verde. However, no seasonal $\delta \mathrm{D}$ cycle could be observed at Schauinsland, which likely reflects the larger influence of local sources and sinks at this continental station.
\end{abstract}

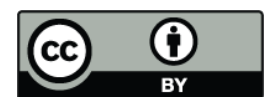

Correspondence to: A. M. Batenburg (a.m.batenburg@uu.nl)
At the two SH stations, no seasonal cycle could be detected in the $\delta \mathrm{D}$ data. If it is assumed that the sink processes are the main drivers of the observed seasonality in $m\left(\mathrm{H}_{2}\right)$ and $\delta \mathrm{D}$ on the $\mathrm{NH}$, the relative seasonal variations can be used to estimate the relative sink strength of the two major sinks, deposition to soils and atmospheric oxidation by the hydroxyl $(\mathrm{OH})$ radical. For the NH coastal and marine stations this analysis suggests that the relative contribution of soil uptake to the total annual $\mathrm{H}_{2}$ removal increases with latitude.

\section{Introduction}

Molecular hydrogen $\left(\mathrm{H}_{2}\right)$ is present in the atmosphere with a typical mixing ratio $\left(m\left(\mathrm{H}_{2}\right)\right)$ of more than $500 \mathrm{ppb}$ (nmole mole ${ }^{-1}$ ) (Glueckauf and Kitt, 1957; Schmidt and Seiler, 1970; Schmidt, 1974; Ehhalt et al., 1977). Over the last decades, several studies examined the magnitude of the source and sink terms in the global $\mathrm{H}_{2}$ budget (Novelli et al., 1999; Hauglustaine and Ehhalt, 2002; Sanderson et al., 2003; Rhee et al., 2006b; Price et al., 2007; Xiao et al., 2007; Ehhalt and Rohrer, 2009; Pieterse et al., 2011, Yashiro et al., 2011, see Table 1 for the budgets that included isotopes). These show that the largest $\mathrm{H}_{2}$ sources are the atmospheric oxidation of methane and other hydrocarbons, and combustion processes. Production by nitrogen-fixing bacteria, on land or in the oceans, constitutes a smaller source. About three quarters of the $\mathrm{H}_{2}$ thus produced is taken up by soil; the other quarter is oxidized by the hydroxyl radical $(\mathrm{OH})$. However, large quantitative uncertainties still exist in the global $\mathrm{H}_{2}$ budget. For example, the estimates for the sink strength

Published by Copernicus Publications on behalf of the European Geosciences Union. 
Table 1. The global budget of atmospheric $\mathrm{H}_{2}$, with source and sink strengths and isotopic signatures used by different authors.

\begin{tabular}{|c|c|c|c|c|c|c|}
\hline \multirow[b]{2}{*}{ Sources } & \multicolumn{2}{|c|}{ Rhee et al. (2006) } & \multicolumn{2}{|c|}{ Price et al. (2007) } & \multicolumn{2}{|c|}{ Pieterse et al. (2011) } \\
\hline & $\begin{array}{r}\text { Source strength } \\
\left(\mathrm{Tg} \mathrm{H}_{2} \mathrm{a}^{-1}\right)\end{array}$ & $\begin{array}{r}\text { Source signature } \\
(\%)\end{array}$ & $\begin{array}{r}\text { Source strength } \\
\qquad\left(\mathrm{Tg} \mathrm{H}_{2} \mathrm{a}^{-1}\right)\end{array}$ & $\begin{array}{r}\text { Source signature } \\
(\% o)\end{array}$ & $\begin{array}{r}\text { Source strength } \\
\left(\mathrm{Tg} \mathrm{H}_{2} \mathrm{a}^{-1}\right)\end{array}$ & $\begin{array}{r}\text { Source signature } \\
(\%)\end{array}$ \\
\hline Fossil fuel burning & $15 \pm 6$ & -270 & 18.3 & -196 & $17.0_{-6}^{+3}$ & -196 \\
\hline Biomass burning & $16 \pm 3$ & -90 & 10.1 & -290 & $15.0_{-5}^{+5}$ & -260 \\
\hline Biofuel & & & 4.4 & -290 & & \\
\hline Ocean & $6 \pm 5$ & -700 & 6 & -628 & $5.0_{-2}^{+1}$ & -628 \\
\hline Land $\mathrm{N}_{2}$ fixation & $6 \pm 5$ & -700 & 0 & & $3.0_{-3}^{+3}$ & -628 \\
\hline Methane oxidation & $64 \pm 12$ & +190 & 24.5 & +162 & 37.3 & +116 \\
\hline VOC oxidation & (incl. VOC) & & 9.8 & +162 & & \\
\hline \multirow{3}{*}{ Sinks } & & Sink fractionation & & Sink fractionation & & Sink fractionation \\
\hline & Sink strength & factor & Sink strength & factor & Sink strength & factor \\
\hline & $\left(\mathrm{Tg} \mathrm{H}_{2} \mathrm{a}^{-1}\right)$ & $\left(\alpha=k_{\mathrm{HD}} / k_{\mathrm{H}_{2}}\right)$ & $\left(\mathrm{Tg} \mathrm{H}_{2} \mathrm{a}^{-1}\right)$ & $\left(\alpha=k_{\mathrm{HD}} / k_{\mathrm{H}_{2}}\right)$ & $\left(\mathrm{Tg} \mathrm{H}_{2} \mathrm{a}^{-1}\right)$ & $\left(\alpha=k_{\mathrm{HD}} / k_{\mathrm{H}_{2}}\right)$ \\
\hline Uptake by soils & $88 \pm 11$ & $0.943 \pm 0.007$ & 55 & 0.943 & 55.8 & 0.925 \\
\hline Oxidation by $\mathrm{OH}$ & $19 \pm 3$ & $0.58 \pm 0.07$ & 18 & 0.568 & 22.1 & 0.542 \\
\hline
\end{tabular}

of soil uptake - the largest term in the budget - vary widely between these studies.

Research into the atmospheric $\mathrm{H}_{2}$ budget has increased in recent years, because $\mathrm{H}_{2}$ may become an important energy carrier in the future. In this case, emissions of $\mathrm{H}_{2}$ to the atmosphere are likely to rise as a result of the inevitable leakage during production, storage and distribution of $\mathrm{H}_{2}$ (Schultz et al., 2003). The associated rise of atmospheric $\mathrm{H}_{2}$ levels is expected to affect the oxidative capacity of the atmosphere, with implications for the atmospheric lifetime of many species, including the strong greenhouse gas methane. Higher concentrations of $\mathrm{H}_{2}$ will also affect stratospheric ozone levels, although estimates of the impact vary significantly among authors (Tromp et al., 2003; Warwick et al., 2004; Feck et al., 2008).

Due to the large relative mass difference between deuterated hydrogen (HD) and non-deuterated hydrogen (HH), particularly large isotope effects occur in the chemical processes that produce or remove $\mathrm{H}_{2}$. These result, for example, in very different isotopic signatures for $\mathrm{H}_{2}$ produced by combustion processes, by oxidation sources or by biological processes (see Table 1). For this reason, determination of the isotopic composition is a promising addition to $m\left(\mathrm{H}_{2}\right)$ observations to distinguish between different $\mathrm{H}_{2}$ source and sink processes and to constrain the terms in the global budget. In this paper, the following definition of $\delta \mathrm{D}$ is used to indicate the isotopic composition of the hydrogen:

$\delta \mathrm{D}=\delta\left(\mathrm{D}, \mathrm{H}_{2}\right)=\left(\frac{R_{\text {Sample }}}{R_{\text {VSMOW }}}-1\right) \cdot 1000 \%$ o

where $R_{\text {Sample }}$ is the ratio of the number density of "heavy" deuterium atoms (D) to the number density of "light" hydrogen atoms $(\mathrm{H})$ in the $\mathrm{H}_{2}$ of the sample, and $R_{\mathrm{VSMOW}}$ is the ratio of the number density of deuterium atoms to the number density of $\mathrm{H}$ atoms in Vienna Standard Mean Ocean Water, which is $(155.75 \pm 0.08) \mathrm{ppm}$ (De Wit et al., 1980; Gonfiantini et al., 1993). Note that the \%o-sign is explicitly included in this formula.

Following up the initial work by (Ehhalt, 1966; Gerst and Quay, 2000, 2001), new analytical techniques that have become available recently have significantly simplified $\mathrm{H}_{2}$ isotope analysis so that many more data have become available in the past few years (Rahn et al., 2002b; Rhee et al., 2004). This has led to new constraints on the isotopic signatures of the most important sources and sinks. The isotopic composition of $\mathrm{H}_{2}$ from $\mathrm{CH}_{4}$ oxidation was first examined by measurements in the stratosphere (Rahn et al., 2003; Röckmann et al., 2003; Rhee et al., 2006a), but also individual steps in the oxidation sequence have been investigated, especially photolysis of formaldehyde (HCHO) (Feilberg et al., 2007; Mar et al., 2007; Nilsson et al., 2007; Rhee et al., 2008; Röckmann et al., 2010b). Furthermore, more information on the main surface sources, biomass burning and fossil fuel combustion (Röckmann et al., 2010a; Vollmer et al., 2010) and the largest sink, uptake in soil (Rahn et al., 2002a; Gerst and Quay, 2001; Rice et al., 2011), has become available.

At the same time, $\mathrm{H}_{2}$ and $\delta \mathrm{D}$ have been incorporated into chemical transport models (Price et al., 2007; Pieterse et al., $2009,2011)$. Until now, $\delta \mathrm{D}$ observations to validate these model results have been scarce. Data have been published from Pacific Ocean transects, the Cheeka Peak observatory (Washington, US), the Point Barrow observatory (Alaska, US) and the CARIBIC aircraft sampling program (Gerst and Quay, 2000; Rhee et al., 2006b; Rice et al., 2010). These datasets have limited spatial coverage and temporal resolution, most notably in the higher latitudes of the NH. Here 
we present observations from six ground stations covering high latitudes of both the $\mathrm{NH}$ and $\mathrm{SH}$ and all seasons, that contribute to the closing of this observational gap. The interpretation of the isotope record we present here is semiquantitative. A more rigorous quantification of the terms in the global budget will require the use of the aforementioned global chemistry models. Our data have already been used with the global chemistry transport model TM5 (Pieterse et al., 2011).

\section{Experimental}

Air samples were collected by the Institut für Umweltphysik of the University of Heidelberg (UHEI-IUP), the Max Planck Institute for Biogeochemistry in Jena (MPI-BGC) and the Laboratoire des Sciences du Climat et de l'Environnement in Gif sur Yvette (LSCE) at the six stations listed in Table 2 and depicted in Fig. 1. These six stations are part of the EUROpean network for atmospheric HYDRogen Observations and Studies (EUROHYDROS) (Engel, 2009). 11 or 21 borosilicate 3.3 glass flasks with Kel-F (PCTFE) O-ring-sealed stopcocks (Normag) were used for most of the samples. This type of flask is known to be stable for a number of trace gases (Rothe et al., 2004). Storage tests performed at the MPI-BGC indicated that - except for a few individual outliers $-m\left(\mathrm{H}_{2}\right)$ is also stable in these flasks. Only for Amsterdam Island, an older type of flask with Teflon PFA O-rings was sometimes used until May 2007. Most flasks were covered with a black shrink hose, and all flasks were stored in closed metal boxes when not in use, minimizing photochemical $\mathrm{H}_{2}$ production after sampling.

The flasks used for sampling at Alert, Schauinsland and Neumayer (operated by UHEI-IUP) were conditioned by flushing with dry air (dewpoint of $-76^{\circ} \mathrm{C}$ ) over two hours on two consecutive days. During sample collection the flask air was dried cryogenically, to a dewpoint of $-70^{\circ} \mathrm{C}$ for Alert and Neumayer and a dewpoint of $-40^{\circ} \mathrm{C}$ for Schauinsland. The flasks were flushed for at least $15 \mathrm{~min}$ and then pressurized to $\approx 2$ bar (absolute pressure) with KNF Neuberger pumps (type N86KNDC with EPDM membrane).

The flasks used for sampling at Mace Head and Amsterdam Island (operated by LSCE) were evacuated and filled with dry air between each sampling round. At the measurement sites, they were flushed for $10 \mathrm{~min}$ and then filled to $\approx 2$ bar (absolute pressure). For these flasks, more information can be found in (Yver, 2010).

The flasks used for sampling at Cape Verde (operated by MPI-BGC) were conditioned by evacuating at $70^{\circ} \mathrm{C}$ for three days, followed by flushing with 301 of dried ambient air before the first use, and reconditioned between each sampling round by flushing with dried ambient air at 1.6 bar. They were pressurized to 1.6 bar before shipping to Cape Verde, and flushed with the sample air before pressurizing with a membrane pump. The sample air was dried with $\mathrm{Mg}\left(\mathrm{ClO}_{4}\right)_{2}$.

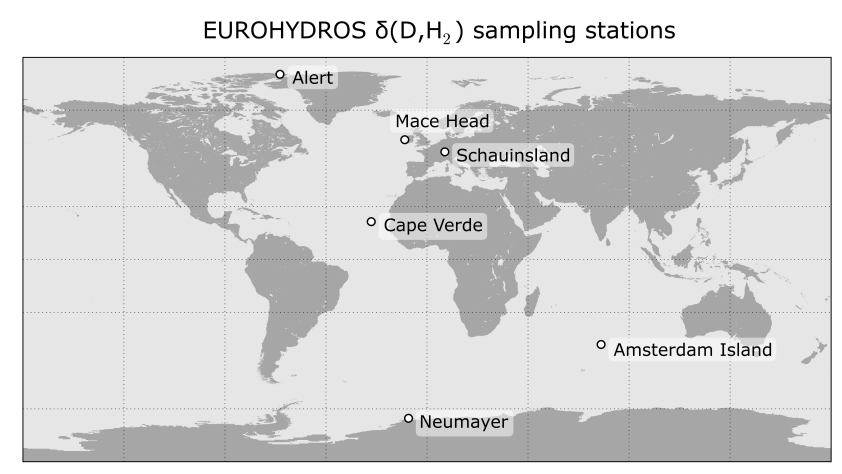

Fig. 1. The six EUROHYDROS stations that were used for $\delta \mathrm{D}$ observations.

The samples were first shipped to the institute that operated the station, where mixing ratios of $\mathrm{H}_{2}$ and other trace gases were measured. $\mathrm{H}_{2}$ mixing ratios were determined with reduction gas analysers, either the RGA-3 (Trace Analytics Inc.) or the Peak Performer 1 RCP (Peak Laboratories) (Hammer and Levin, 2009; Yver et al., 2009; Jordan and Steinberg, 2011). Reduction gas analysers separate reduced gases such as $\mathrm{H}_{2}$ from the air matrix by gas chromatography, and then quantify them via a redox reaction with mercuric oxide and detection of the resulting mercury vapour by UV absorption. We give mixing ratios in units of "parts per billion" (ppb, equivalent to the SI-unit "nmole mole ${ }^{-1}$ "). All laboratories used laboratory working standards that are now on the MPI2009 scale, developed at the MPI-BGC (Jordan and Steinberg, 2011). The samples were then shipped to the isotope laboratory at the Institute for Marine and Atmospheric Research (IMAU) of Utrecht University. Typically, several months passed between sample collection and isotope analysis. A total of 480 flasks were analysed; the number of samples per station is listed in Table 2.

In Utrecht, a gas chromatography isotope-ratio mass spectrometry (GC-IRMS) system as described in (Rhee et al., 2004) is used to separate $\mathrm{H}_{2}$ from the air matrix and to determine its isotopic composition in a four-step procedure, as follows:

- A $\approx 750 \mathrm{ml}$ glass sample volume is filled with sample air until pressure in the volume has reached $\approx 700$ mbar. This sample air is then exposed to a Cold Head cooled by a liquid helium compressor to $\approx 40 \mathrm{~K}$, so that all except the most volatile gases $\left(\mathrm{H}_{2}, \mathrm{He}\right.$ and $\left.\mathrm{Ne}\right)$ condense.

- The remaining volatile gases are flushed with He carrier gas to a pre-concentration trap, consisting of a $1 / 8 \mathrm{inch}$ $(3.2 \mathrm{~mm})$ stainless steel tube filled with $5 \AA$ molecular sieve, immersed in liquid nitrogen, which is cooled down to the triple point of nitrogen $(63 \mathrm{~K})$ by pumping off the gas phase. 
Table 2. The locations and operating institutes of the six EUROHYDROS flask sampling stations discussed here, and the length, average values and maximum variations of their $\mathrm{m}\left(\mathrm{H}_{2}\right)$ and $\delta \mathrm{D}$ sample records.

\begin{tabular}{|c|c|c|c|c|c|c|c|c|}
\hline Station & Coordinates & $\begin{array}{l}\text { Operating } \\
\text { Institute }\end{array}$ & Samples & $\begin{array}{r}\text { Record } \\
\text { length (months) }\end{array}$ & $\begin{array}{l}\text { Average } m \\
\left(\mathrm{H}_{2}\right)(\mathrm{ppb})\end{array}$ & $\begin{array}{r}\text { Max. } m \\
\left(\mathrm{H}_{2}\right) \text { variation }\end{array}$ & $\begin{array}{r}\text { Average } \delta \mathrm{D} \\
(\% \circ \text { vs. VSMOW) }\end{array}$ & $\begin{array}{l}\text { Max. } \delta \mathrm{D} \\
\text { variation }\end{array}$ \\
\hline Alert & $82^{\circ} 28^{\prime} \mathrm{N} 62^{\circ} 30^{\prime} \mathrm{W}$ & UHEI-IUP & 194 & 47 & $496.9 \pm 1.2$ & 131 & $124.1 \pm 0.5$ & 41 \\
\hline Mace Head & $53^{\circ} 20^{\prime} \mathrm{N} 9^{\circ} 54^{\prime} \mathrm{W}$ & LSCE & 71 & 41 & $518.3 \pm 1.4$ & 72 & $121.2 \pm 0.7$ & 34 \\
\hline Cape Verde & $16^{\circ} 52^{\prime} \mathrm{N} 24^{\circ} 52^{\prime} \mathrm{W}$ & MPI-BGC & 42 & 12 & $538.3 \pm 1.3$ & 57 & $119.9 \pm 1.1$ & 36 \\
\hline Amsterdam Island & $37^{\circ} 48^{\prime} \mathrm{S} 77^{\circ} 32^{\prime} \mathrm{E}$ & LSCE & 63 & 38 & $549.5 \pm 0.6$ & 28 & $143.8 \pm 1.0$ & 32 \\
\hline Neumayer & $70^{\circ} 39^{\prime} \mathrm{S} 8^{\circ} 15^{\prime} \mathrm{W}$ & UHEI-IUP & 110 & 59 & $551.1 \pm 0.4$ & 30 & $149.8 \pm 0.4$ & 18 \\
\hline
\end{tabular}

- After pre-concentration the trap is lifted from the liquid nitrogen and the trapped gases are flushed to a cryofocus trap. This trap consists of a molsieve $5 \AA$ capillary column, jacketed in a stainless steel tube and immersed in liquid nitrogen at ambient pressure $(77 \mathrm{~K})$. After focussing, the trap is lifted from the liquid nitrogen and the gases are injected into a $5 \AA$ molsieve Gas Chromatography column kept in an oven at $50^{\circ} \mathrm{C}$, where the $\mathrm{H}_{2}$ is separated from any potential contaminants.

- The purified $\mathrm{H}_{2}$ is then injected through an open split system into the IRMS (ThermoFinnigan Delta plus XL) for determination of the $\mathrm{D} / \mathrm{H}$ ratio.

In the IRMS chromatogram, The sample peak was typically bracketed by seven $\mathrm{H}_{2}$ laboratory working gas peaks of pure $\mathrm{H}_{2}$ before and two $\mathrm{H}_{2}$ working gas peaks after. By the same procedure as for the samples, comparable quantities of air from laboratory reference air bottles were typically measured twice a day. The $\mathrm{H}_{2}$ mixing ratio in the laboratory reference bottle that was in use from March 2007 until February 2010 was determined by UHEI-IUP to be $(546.2 \pm 2.5) \mathrm{ppb}$, later confirmed by MPI-BGC to be $(545.0 \pm 0.5) \mathrm{ppb}$. Its $\delta \mathrm{D}((+73.0 \pm 1.8) \%$, where the error bar indicates one standard error from 5 different determinations) was calculated using mixtures of synthetic air with $\mathrm{H}_{2}$ of known isotopic composition $((-9.5 \pm 0.5) \%$ and $(+205 \pm 2) \%$ o, certified by Messer Griesheim, Germany) that were measured on the GCIRMS system on the same days as the laboratory reference bottle. When this laboratory reference air bottle became exhausted, it was replaced with two other mixtures of synthetic air and $\mathrm{H}_{2}((580.78 \pm 0.03) \mathrm{ppb}$ and $(244.3 \pm 0.8) \mathrm{ppb}$, as determined by BGC Jena) that were regularly measured from December 2008 onward. From measurements during the overlap period, the isotopic composition of these new reference gases was calibrated versus the old reference air bottle $((+207.0 \pm 0.3) \% o$ and $(+198.2 \pm 0.5) \% o)$. Inspection of these measurements also allowed a robust assessment of the reproducibility of our system yielding a standard deviation of $4.5 \%$ in $\delta \mathrm{D}$. It should be borne in mind that the error estimates given here are estimates of the random error due to measurement scatter only. The determination of $\delta\left(\mathrm{D}, \mathrm{H}_{2}\right)$ of the laboratory reference air bottle comprises additional systematic uncertainties, e.g. the correctness of the initially assigned $\delta\left(\mathrm{D}, \mathrm{H}_{2}\right)$ values of the commercial calibration gases, changes of these values in the process of creating calibration mixtures with near-ambient $m\left(\mathrm{H}_{2}\right)$, and the calibration measurements themselves. This may lead to an additional systematic error of a few $\%$.

The measurements of the laboratory reference bottles were used to construct 5-day moving average values of measured $\delta \mathrm{D}$ values and the deviation of the measured from the assigned $\delta \mathrm{D}$ value for each measurement day. The moving average of the laboratory reference bottle measurements was replaced by the average of an adjusted selection of these measurements for those days around which a relatively sudden shift in the measured values seemed to occur. An empirical scale contraction factor (1.0613) was determined from the measurements of the mixtures of synthetic air with $\mathrm{H}_{2}$ of known isotopic composition. This factor was used to determine the corrected $\delta \mathrm{D}$ value for the sample measurements by inter- or extrapolation from the 5-day moving average values of the reference gas results for that day. (It was assumed that the GC-IRMS follows a linear response curve.)

A blank measurement was usually performed once a day as well. The blank peak area was usually less than $4 \%$ of a typical sample peak area. Due to the small peak area, the $\delta \mathrm{D}$ value of the blank could not be determined reliably from these measurements and could therefore not be taken into account in the calculation of the sample $\delta \mathrm{D}$ values. The contribution of the blank signal to the random scatter is included in the $4.5 \%$ reproducibility that is obtained for repeated measurements of the laboratory reference air bottle. However, the blank may cause an unquantified systematic error.

The laboratory reference bottle and blank measurements were used to calculate $m\left(\mathrm{H}_{2}\right)$ for the samples as well. Mixing ratios determined by GC-IRMS measurement typically deviated less than $4 \%$ from the determinations by RGA-3 or Peak Performer. They were used for quality assessment of the data, but are not considered further in this paper. 
Despite these calibration measures, $\delta \mathrm{D}$ measurements from June 2010 onwards seemed to have a positive offset with respect to the previously measured samples and an increased scatter. By comparing the respective samples from stations with long data series (Alert and Neumayer) with measurements from previous years, the offset was empirically determined to be on average $9.5 \%$ o. Unfortunately, it could not be determined whether the offset was caused by simultaneous drift in the two laboratory reference bottles in use at that time or by the replacement of parts of the setup. At present the system is undergoing substantial rebuilding and further automation in order to be able to accommodate more reference gas measurements in the future.

The affected measurements of Alert and Neumayer samples still showed the same seasonal patterns as the previous measurements, and were therefore adjusted to fall on the same scale as the previous data by subtracting the empirically determined $9.5 \%$ offset. The respective data are indicated with open symbols in Fig. 2. Cape Verde samples that were also measured during this period showed a more erratic behaviour and were therefore omitted from the time series presented here. The Schauinsland samples collected after September 2009 showed strong pollution signatures (high mixing ratios, as determined by both RGA-3 and GC-IRMS measurements, and very low $\delta \mathrm{D}$ values), which coincided with $\mathrm{CO}_{2}$ contaminations. As a leak or contamination in the sampling system was suspected, these data were also omitted.

Some of the $m\left(\mathrm{H}_{2}\right)$ and $\delta \mathrm{D}$ data points seem to fall outside of the normal range of variation at the respective sampling station. For several of these outliers, we have looked into back-trajectory calculations (see Sect. 3.1.2) to determine if the origin of these air parcels was unusual, but no clear conclusions could be derived from this analysis. Therefore, we have selected outliers based only on visual inspection of the time series. These data points are indicated with open stars in Fig. 2. The data indicated with open symbols in Fig. 2 (the outliers and the samples measured after June 2010) are not used in further calculations.

\section{Results and discussion}

\subsection{Time series}

The time series of $m\left(\mathrm{H}_{2}\right)$ and $\delta \mathrm{D}$ for all six stations are shown in Fig. 2, and will be discussed individually in the following subsections. Figure 3 shows the seasonal averages from which an annual average was calculated for each station. Using the seasonal averages rather than the raw data for calculation of the mean has the advantage that each of the seasons (DJF, MAM, JJA, SON) has equal weight, which avoids bias from having more samples from some seasons than from others.
Least-squares harmonic fits were applied to the $m\left(\mathrm{H}_{2}\right)$ and $\delta \mathrm{D}$ data of the three stations that showed the clearest seasonal cycles in $\delta \mathrm{D}$. We use the function:

$y=a \cos (2 \pi(x-\varphi))+m$

where $x$ is the time in years and $a$ (amplitude), $\varphi$ (phase) and $m$ (average value) are the fitting parameters. A term for a possible temporal trend is not included in the fit function because our time series of $\mathrm{H}_{2}$ and $\delta \mathrm{D}$ are still relatively short. The results (listed in Table 3 ) were used to construct the ellipses in the phase diagrams in Fig. 6.

\subsubsection{Alert}

Alert is the station with the largest number of analysed samples (Table 2) and about four full seasonal cycles of data. The annual average values are $m\left(\mathrm{H}_{2}\right)=(496.9 \pm 1.2) \mathrm{ppb}$, and $\delta \mathrm{D}=(124.1 \pm 0.5) \%$, where the error bar indicates the standard error of the mean (the standard deviation as a result of the variance in the measurements, divided by the square root of the number of measurements). A difference of $131 \mathrm{ppb}$ is found between the highest and lowest $m\left(\mathrm{H}_{2}\right)$ value, as well as a difference of $41 \%$ o between the highest and lowest $\delta \mathrm{D}$ (excluding the measurements affected by the $9.5 \%$ offset and outliers for $\delta \mathrm{D})$.

A distinct seasonal cycle is observed for both $m\left(\mathrm{H}_{2}\right)$ and $\delta \mathrm{D}$ (Fig. 2). The two quantities clearly increase and decrease out-of-phase. This out-of-phase timing results from the seasonal variations of the mainly deuterium-depleted (combustion) sources and the deuterium-enriching removal processes. Photochemically produced $\mathrm{H}_{2}$ can contribute to $m\left(\mathrm{H}_{2}\right)$ changes, but contributes little to changes in $\delta \mathrm{D}$, since its $\delta \mathrm{D}$ value is relatively close to ambient $\delta \mathrm{D}$ values. So, in winter, $\mathrm{H}_{2}$ accumulates from depleted sources, leading to an $m \mathrm{H}_{2}$ peak and a $\delta \mathrm{D}$ minimum in spring, while during summer, the removal processes are strong and the remaining $\mathrm{H}_{2}$ becomes enriched, leading to an $m \mathrm{H}_{2}$ minimum and $\delta \mathrm{D}$ maximum in autumn. The detailed study of the global $\mathrm{H}_{2}$ isotope budget with the TM5 model (Pieterse et al., 2011) shows that the soil sink contributes most to the seasonal cycle of the mixing ratio, while the smaller photochemical sink has a slightly larger effect on the isotopic composition, due to the larger isotope fractionation. The emissions from combustion sources are not strongly seasonal. Photochemical production does have a seasonal cycle, but contributes little to the variations in $\delta \mathrm{D}$.

The phase of the least-square harmonic fits to the Alert $m\left(\mathrm{H}_{2}\right)$ data (Table 3) is similar to the phase reported by Rhee et al. (2006b) for the cycle of NH near-tropopause averages of $m\left(\mathrm{H}_{2}\right)$ obtained from three flights with a passenger aircraft, whereas the phase found for the $\delta \mathrm{D}$ cycle is slightly different (the Alert $\delta \mathrm{D}$-cycle is slightly ahead of the (Rhee et al., 2006b) cycle). The average mixing ratio is lower. The most striking difference is in the amplitudes; the amplitudes of the seasonal cycles found at Alert are larger than for the 


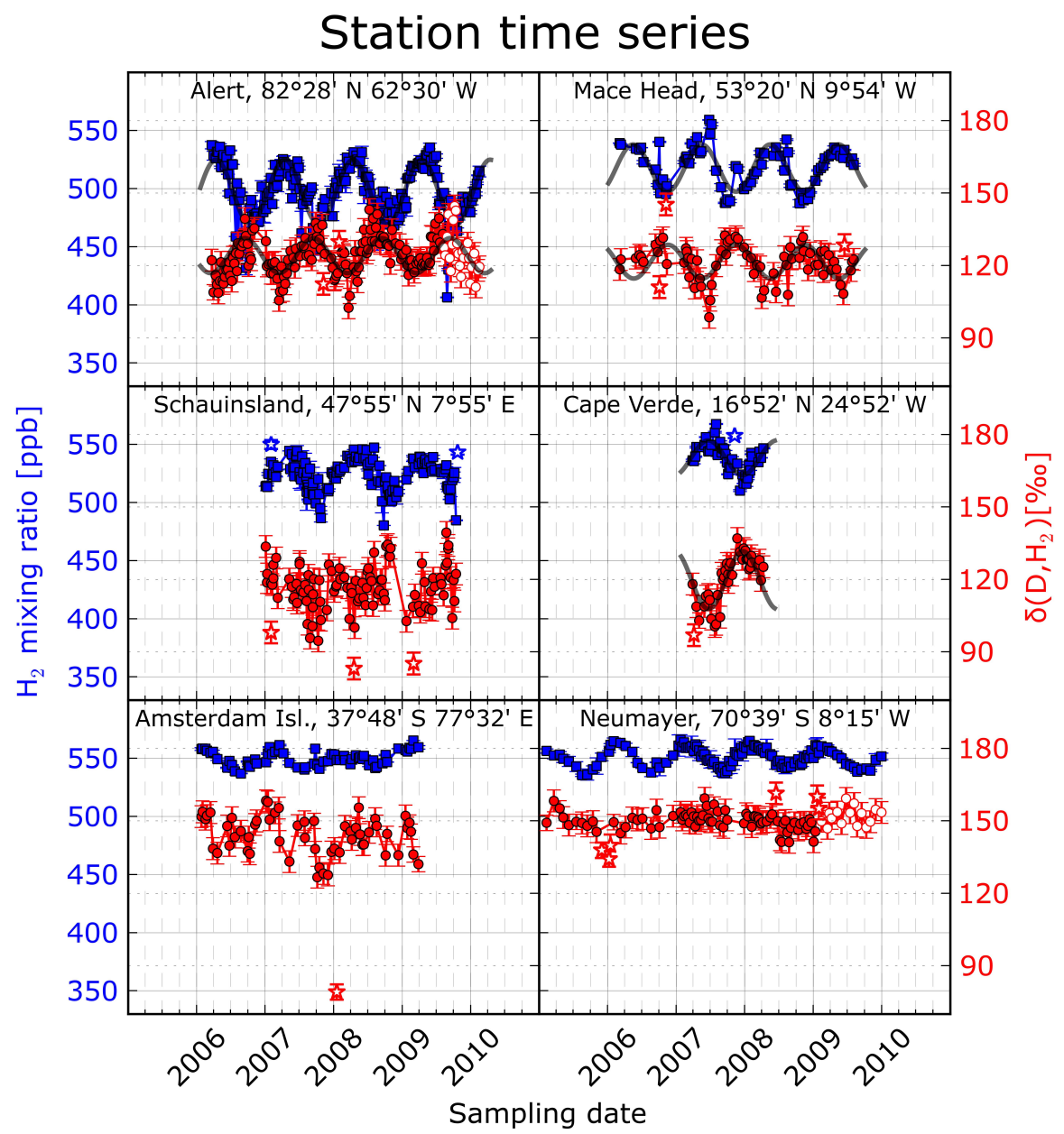

Fig. 2. $m\left(\mathrm{H}_{2}\right)$ (blue squares, measured by UHEI-IUP, LSCE and MPI-BGC) and $\delta$ D (red circles) measured by IMAU on samples from the six stations. Solid grey lines represent a harmonic best fit to the data from Alert, Mace Head and Cape Verde. Error bars indicate one standard deviation for $m\left(\mathrm{H}_{2}\right)$ determined from successive measurements, and one standard error for $\delta \mathrm{D}$ (the standard deviation of $4.5 \%$, as determined from repeated laboratory standard bottle measurements, divided by the square root of the number of repeat measurements of the same flask). Open red circles indicate the $\delta \mathrm{D}$-values where an empirical value of $9.5 \%$ was subtracted to adjust for the bias that affected the GC-IRMS system from June 2010 onward. Open blue and red stars indicate other unexplained outliers in $m\left(\mathrm{H}_{2}\right)$ and $\delta \mathrm{D}$, respectively. None of the open-symbol data are used in any further calculations. Some outliers at Amsterdam Island are off the scale.

Rhee et al. (2006b) NH near-tropopause averages, even more so since on visual inspection the harmonic fit seems to underestimate the amplitudes. The larger amplitudes can likely be attributed to the larger seasonality in the sinks at higher $\mathrm{NH}$ latitudes, due to the larger relative soil surface and the seasonal snow cover variation that modulates the soil sink. As we will show below, for the high-latitude NH stations, soil uptake dominates the seasonal cycle more than at lower $\mathrm{NH}$ latitudes. It seemingly also dominates the Alert seasonal cycle more than the NH high tropospheric average cycle. In a modelling study that focused on $\mathrm{H}_{2}$ uptake by soil, Yashiro et al. (2011) found that the soil uptake flux for the latitude range north of $45^{\circ} \mathrm{N}$ has a much larger seasonal variation than for the $15^{\circ} \mathrm{N}$ to $45^{\circ} \mathrm{N}$ latitude range, which is in accordance with this finding. However, it should be noted that the analysis of Rhee et al. (2006b) is based on fitting a harmonic function to three data points only, whereas the Alert data series clearly captures the full seasonal evolution of the isotope signal.

Gerst and Quay (2000) published six $\delta$ D measurements on samples from another high northern latitude station, Point Barrow, Alaska, collected in the period from February to August 1997. Unexpectedly, the $\delta \mathrm{D}$ values of $(+92 \pm 10) \%$, (one standard deviation) at Point Barrow are significantly lower than what we find at Alert and other NH stations (see below). The reason for this discrepancy is not understood, and the TM5 model (Pieterse et al., 2011) does not predict such a large difference either. It should be noted, however, that in-cylinder growth of $\mathrm{H}_{2}$ is an issue in the early data from Gerst and Quay (2000). Specifically, four other samples from 
Table 3. The obtained fitting parameters for a least-square fit with a harmonic function to the data from Alert, Mace Head and Cape Verde $(y=a \cos (2 \pi(x-\phi))+m)$.

\begin{tabular}{l|rr|rr|rr|r|r}
\hline & \multicolumn{2}{|c|}{ Alert } & \multicolumn{2}{c|}{ Mace Head } & \multicolumn{2}{c}{$\begin{array}{c}\text { Cape Verde } \\
\text { Rhee et al., 2006b) } \\
\text { NH hemisphere average }\end{array}$} \\
\hline & $\mathrm{m}\left(\mathrm{H}_{2}\right)(\mathrm{ppb})$ & $\delta \mathrm{D}(\% \circ)$ & $\mathrm{m}\left(\mathrm{H}_{2}\right)(\mathrm{ppb})$ & $\delta \mathrm{D}(\%)$ & $\mathrm{m}\left(\mathrm{H}_{2}\right)(\mathrm{ppb})$ & $\delta \mathrm{D}(\%)$ & $\mathrm{m}\left(\mathrm{H}_{2}\right)$ \\
\hline Amplitude $(a)$ & $27.8 \pm 1.4$ & $7.3 \pm 0.7$ & $20.3 \pm 1.9$ & $7.0 \pm 1.0$ & $15.0 \pm 1.7$ & $12.0 \pm 1.2$ & $18.2 \pm 1.6$ & $4.0 \pm 0.9$ \\
Phase $(\phi)$ & $0.24 \pm 0.01$ & $0.66 \pm 0.02$ & $0.33 \pm 0.01$ & $0.84 \pm 0.02$ & $0.43 \pm 0.02$ & $0.94 \pm 0.02$ & $0.28 \pm 0.01$ & $0.85 \pm 0.05$ \\
Average $(m)$ & $497.0 \pm 1.0$ & $124.1 \pm 0.5$ & $517.6 \pm 1.3$ & $121.6 \pm 0.7$ & $538.4 \pm 1.1$ & $119.7 \pm 0.8$ & $543.4 \pm 0.8$ & $128.3 \pm 0.7$ \\
\hline
\end{tabular}

Point Barrow in the study from Gerst and Quay (2000) were considered contaminated since their mixing ratios differed by more than $3 \sigma$ from a multi-year average of NOAA-CMDL data. All samples were measured more than one year after collection and the discrepancy to the new values from Alert may indicate that the six samples considered reliable may have been contaminated too. The isotopic composition of the cylinder grown contamination was determined by (Gerst and Quay, 2000) to be $\delta \mathrm{D}=-614 \%$, and thus only a few $\%$ of contamination from this source could lead to the observed depletions.

\subsubsection{Mace Head}

The time series for Mace Head span more than three years now. The maximum amplitudes are $72 \mathrm{ppb}$ and $34 \%$ for $m\left(\mathrm{H}_{2}\right)$ and $\delta \mathrm{D}$, respectively and the annual averages are $(518.3 \pm 1.4) \mathrm{ppb}$ and $(121.2 \pm 0.7) \%$ o. $m\left(\mathrm{H}_{2}\right)$ shows a clear seasonal cycle; it increases steadily from autumn until summer, and then decreases rapidly. The $\delta \mathrm{D}$ time series in 2007 and 2008 shows a minimum in late spring or early summer, indicating a seasonal cycle in $\delta \mathrm{D}$ at Mace Head, which is also predicted by the TM5 model (Pieterse et al., 2011). In general, the $\delta \mathrm{D}$ cycle moves in antiphase to the $m\left(\mathrm{H}_{2}\right)$ cycle, as discussed above for Alert. However, it can be seen from the seasonal averages (Fig. 3), as well as from the phase obtained from the harmonic fit (Table 3), that the timing of the minimum is delayed with respect to Alert. The phase obtained from the harmonic fit to the Mace Head $\delta \mathrm{D}$ data is in fact closer to the phase found by Rhee et al. (2006b) than the phase obtained from the Alert cycle. Still, as at Alert, the amplitude is larger than that from Rhee et al. (2006b). Mace Head can still be considered to be in the higher latitude part of the NH (especially since it receives much air from regions to the North-West, see below), and this large seasonal variation can thus be attributed to the large seasonal variation in the soil uptake flux at high NH latitudes as well. That this isotopic seasonal cycle is not visible in the first year of the series (2006) may be due to the small number of samples in this year. In 2009 , there is one high $\delta \mathrm{D}$ outlier right in the seasonal minimum. The $\delta \mathrm{D}$ seasonal cycles vary con- siderably between 2007 and 2009, but the same is true for $m\left(\mathrm{H}_{2}\right)$, so what causes the interannual variations in $m\left(\mathrm{H}_{2}\right)$ likely causes the interannual variations in $\delta \mathrm{D}$.

To investigate the origin of the interannual variations, backward trajectories were calculated with the NOAA HYSPLIT model to investigate if the rather high $m\left(\mathrm{H}_{2}\right)$ and low $\delta \mathrm{D}$ values in summer 2007 might have been a result of synoptic conditions that brought more polluted air than usual to the station. Such an effect was not found. The trajectories showed that most air masses that arrive at Mace Head come from either the north Atlantic or the NH northern temperate to boreal regions to the west, and air masses that were sampled in summer 2007 were no exception. Grant et al. (2010) also showed that Mace Head rarely receives air masses from lower latitudes, supporting our limited trajectory study. Therefore, transport of $\mathrm{H}_{2}$-rich and $\delta \mathrm{D}$-depleted air from lower latitudes does not seem a very likely explanation. It is more likely that the full interannual variability in $\mathrm{H}_{2}$ cannot be seen at this station due to the limited time period over which samples have been taken so far.

\subsubsection{Schauinsland}

In the time series from Schauinsland station, the maximum differences are $67 \mathrm{ppb}$ and $45 \%$, and the seasonally weighted average values are $(523.7 \pm 0.8) \mathrm{ppb}$ and $(117.1 \pm 0.9) \%$. This is relatively similar to the values from Mace Head, but the seasonal cycles show differences. At Schauinsland, a clear seasonal cycle is visible in the $m\left(\mathrm{H}_{2}\right)$ data, but not in the $\delta \mathrm{D}$ data. In 2007 , the $\delta \mathrm{D}$ signal seems to trend downward, while in 2008 and 2009 it appears to trend upward. These trends are not statistically significant, though, but they underline that no clear seasonal cycle in $\delta \mathrm{D}$ is present at Schauinsland.

Unlike Alert and Mace Head, Schauinsland is not a coastal but a continental location, close to anthropogenic sources, especially in the Rhine valley, and in the middle of a large land area where deposition to soil occurs. Possibly, significant nitrogen fixation by soil microbes takes place in the surrounding region as well. $\mathrm{H}_{2}$ produced by nitrogen fixers has a very depleted source signature (Table 1), so only a small 


\section{Seasonal averages}

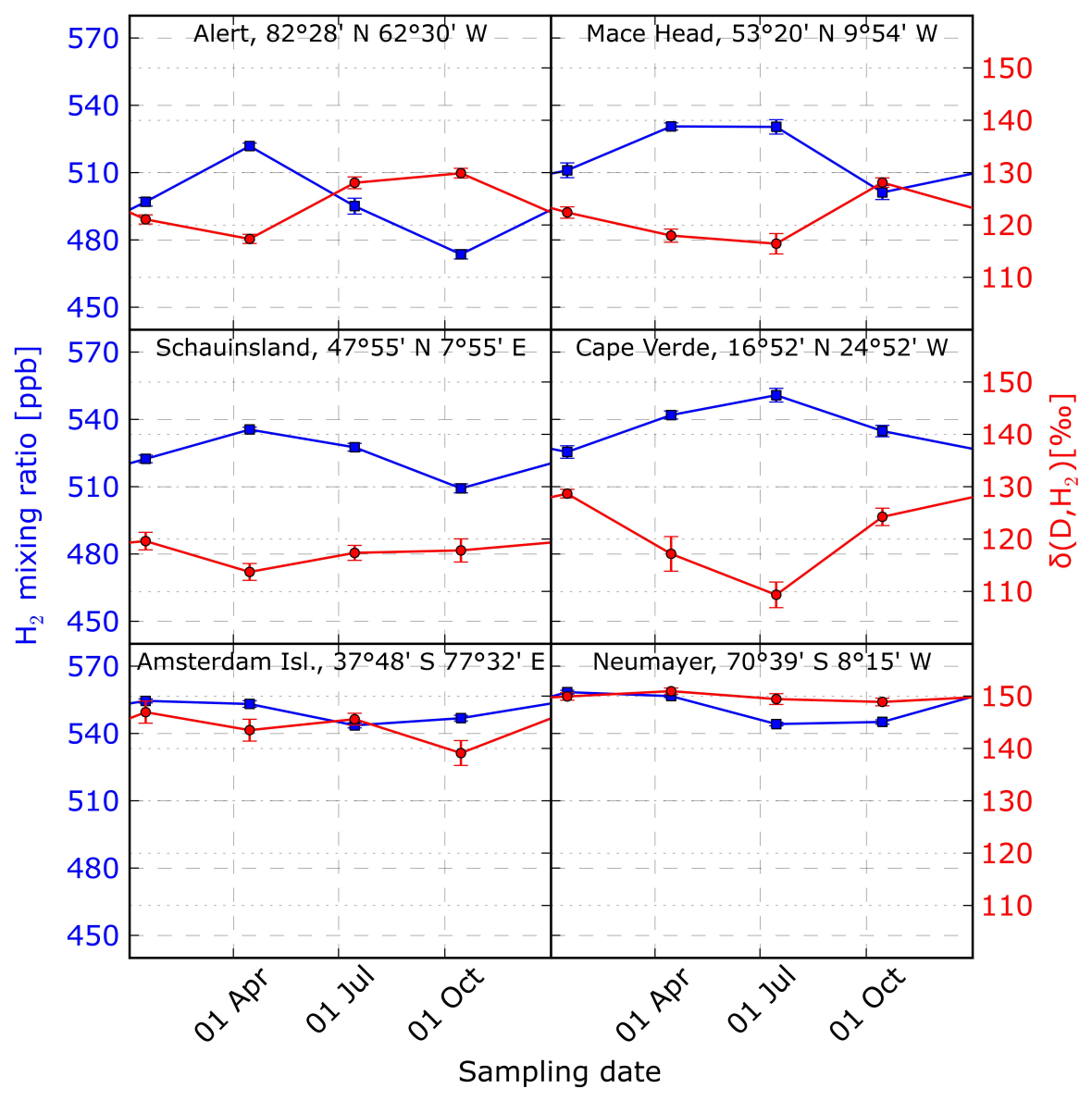

Fig. 3. Seasonal averages of $m\left(\mathrm{H}_{2}\right)$ (UHEI, LSCE and MPI-BGC) and $\delta \mathrm{D}$ (IMAU) plotted versus time of year. Error bars indicate one standard error, which is calculated purely from variance in the values obtained for one season.

amount of this $\mathrm{H}_{2}$ may have a significant effect on the isotopic signature of the total ambient $\mathrm{H}_{2}$. Although this was not investigated in more detail, interannual variations in microbial production may thus contribute to the difference in seasonal patterns between years.

The station is usually above the boundary layer at night, and within the boundary layer during the day, particularly in summer (Schmidt et al., 1996). The upper edge of the boundary layer generally passes the station altitude after 10:00 a.m. (CET), so samples collected after this time are potentially locally influenced; they may contain boundary layer air that has been in contact with local (anthropogenic) sources and the surface. Most of the samples analysed for this record were sampled before 10:00 a.m.; about $10 \%$ was collected later in the day. However, excluding these samples from the time series did not yield a more distinct seasonal cycle. This indicates that the deviations in the isotopic composition are not a product of local factors only. It should be noted that also the TM5 model predicts a considerably smaller seasonal cycle in $\delta \mathrm{D}$ for Schauinsland compared to Mace Head (Pieterse et al., 2011), so a longer time series may be needed to clearly distinguish the cycle from the data scatter.

\subsubsection{Cape Verde}

Although the Cape Verde time series is the shortest (little more than one year), the data indicate a clearer seasonal cycle than at Mace Head. As at Alert and Mace Head, $m\left(\mathrm{H}_{2}\right)$ and $\delta \mathrm{D}$ vary out-of-phase. The timing of the minima and maxima is closer to what is observed at Mace Head than at Alert. The mixing ratio peaked at $567 \mathrm{ppb}$ in August and then decreased by $57 \mathrm{ppb}$ to $510 \mathrm{ppb}$ at the end of the year. From April until August the $\delta \mathrm{D}$ value was rather constant (minimum value of $100 \%$ in July) and after August it increased until the end of the year (maximum observed value $137 \%$ in November). Seasonally weighted annual averages of $(538.3 \pm 1.3) \mathrm{ppb}$ and $(119.9 \pm 1.1) \%$ o were observed. 
The amplitude found with the harmonic fit to the data is remarkably large, larger than for Mace Head and Alert. This contrasts with the TM5 model results (Pieterse et al., 2011) where the seasonal variation in $\delta \mathrm{D}$ at Cape Verde is somewhat smaller than for Mace Head and Alert. However, in Alert and Mace Head, the fit seems to underestimate the amplitudes of the seasonal variation due to differences between years. The amplitude obtained from the fit is apparently dependent on the presence of interannual variations that cannot be detected for Cape Verde (because of the limited length of the measurement record). Therefore, it seems more reasonable in the case of Cape Verde to compare the $\delta \mathrm{D}$ variation in the original data with the other stations (Fig. 2 and Table 2). When these are compared, the seasonal $\delta \mathrm{D}$ variation does not seem exceptionally large in Cape Verde.

The cycles shift to later in the year when moving from Alert to Mace Head to Cape Verde. This can also be seen in the phases obtained from the cosine fits (Table 3). It is possible that seasonal variation in the sources (e.g. tropical biomass burning) or transport (e.g. interhemispheric exchange) contribute to these shifts. Due to the dominant NNW wind direction (trade winds), Cape Verde receives much air from Mauretania and surrounding countries. The biomass burning season in this region is in winter, but we do not see the expected $m\left(\mathrm{H}_{2}\right)$ increase and concomitant $\delta \mathrm{D}$ decrease in this season. Most interhemispheric mixing occurs in summer, when Cape Verde is close to the edge of the ITCZ. Since $\delta$ D values are higher in the SH (Gerst and Quay, 2000, Rice et al., 2010, see also Fig. 4b below), increased transport from the $\mathrm{SH}$ should result in higher $\delta \mathrm{D}$ values, but this is not observed. Therefore, we cannot identify individual source or transport signatures that cause the cycles in Cape Verde to be delayed with respect to the Alert cycles.

\subsubsection{Amsterdam Island}

The time series from Amsterdam Island does not show a very distinct seasonal cycle. $\mathrm{H}_{2}$ mixing ratios only vary between 537 and $565 \mathrm{ppb}$, with seasonal maxima in austral summer, and no clear seasonal signal can be identified in the $\delta \mathrm{D}$ data. This may be due to the remoteness of this location; it is far removed from densely populated areas where anthropogenic $\mathrm{H}_{2}$ is produced, and far away from large land areas where deposition to soil can occur. Other $m\left(\mathrm{H}_{2}\right)$ time series from locations in the Indian Ocean, such as the time series from the Seychelles (in Novelli et al., 1999), also show very small seasonal cycles.

Yashiro et al. (2011) concluded from the timing of the $m\left(\mathrm{H}_{2}\right)$ seasonal cycle that photochemical production is a dominant driver of the seasonality in $m\left(\mathrm{H}_{2}\right)$ south of $30^{\circ} \mathrm{S}$, which is in accordance with the conclusions that Rhee et al. (2006b) drew from $\delta \mathrm{D}$ observations. Since the $\delta \mathrm{D}$ value of photochemically produced $\mathrm{H}_{2}$ is close to ambient values, this does not cause a large seasonality in $\delta \mathrm{D}$. Nonetheless, in austral summer photochemical $\mathrm{H}_{2}$ destruction will occur, with a
D-enriching effect on the reservoir. That we see no seasonal cycle in $\delta \mathrm{D}$ implies that a $\mathrm{D}$-depleting process compensates this enrichment. Transport of depleted $\mathrm{H}_{2}$ from lower latitudes (from tropical biomass burning in $\mathrm{SH}$ spring and interhemispheric exchange) is a likely explanation. The budget calculations made by Pieterse et al. (2011) suggest that transport of depleted $\mathrm{H}_{2}$ from lower latitudes is a significant contributor to the seasonal $\delta \mathrm{D}$ changes in the extratropical $\mathrm{SH}$.

Some unexplained extreme outliers do occur in the measurements. Excluding these outliers, the maximal variability in mixing ratio is $28 \mathrm{ppb}$, and in the isotopic composition $32 \%$. The yearly average values are $(549.5 \pm 0.6) \mathrm{ppb}$ and $(143.8 \pm 1.0) \%$.

\subsubsection{Neumayer}

At present, the Neumayer time series covers 5 full seasonal cycles, and average values are $(551.1 \pm 0.4) \mathrm{ppb}$ and $(149.8 \pm 0.4) \%$ o. A clear seasonal variation can be distinguished in the mixing ratio data, but not in the isotope data. The mixing ratios vary by at most $30 \mathrm{ppb}$ over the year, and the isotope values by at most $18 \%$, making Neumayer the station with the lowest variability in $\delta \mathrm{D}$. A relatively sharp "dip" appears in the $\delta \mathrm{D}$ values at the end of 2005 . This feature was not observed in the other years, so we suspect that this is an artefact rather than a real atmospheric signal and flagged these data points as outliers.

The variation in $\delta \mathrm{D}$ at Neumayer is remarkably small, considering that $m\left(\mathrm{H}_{2}\right)$ does show a clear cycle. As in Amsterdam Island, there is an $m\left(\mathrm{H}_{2}\right)$ maximum in austral summer, likely an effect of photochemical production. That no accompanying change in $\delta \mathrm{D}$ is observed can probably be attributed to the same processes that cause the lack of seasonality in $\delta \mathrm{D}$ at Amsterdam Island: a maximum in photochemical production produces $\mathrm{H}_{2}$ without affecting the $\delta \mathrm{D}$ value much, and the D-enriching effect from photochemical destruction of $\mathrm{H}_{2}$ in summer is balanced by a D-depleting process like transport of depleted $\mathrm{H}_{2}$ from lower latitudes. The timing of these processes is, however, somewhat problematic. According to the TM5 model calculations (Pieterse et al., 2011), horizontal transport has the largest depleting effect on the $\mathrm{H}_{2}$ deuterium content south of $30^{\circ} \mathrm{S}$ in the months July, August and September. This is too early to compensate for the expected enriching effect of photochemical $\mathrm{H}_{2}$ destruction in austral summer. The lack of seasonal variation at Neumayer, and to some extent Amsterdam Island, is therefore not fully explained and requires further study.

\subsubsection{Seasonal mean variations}

Averages per season (December January February (DJF), March April May (MAM), June July August (JJA) and September October November (SON)) were calculated for each station and are shown in Fig. 3. This averaging 


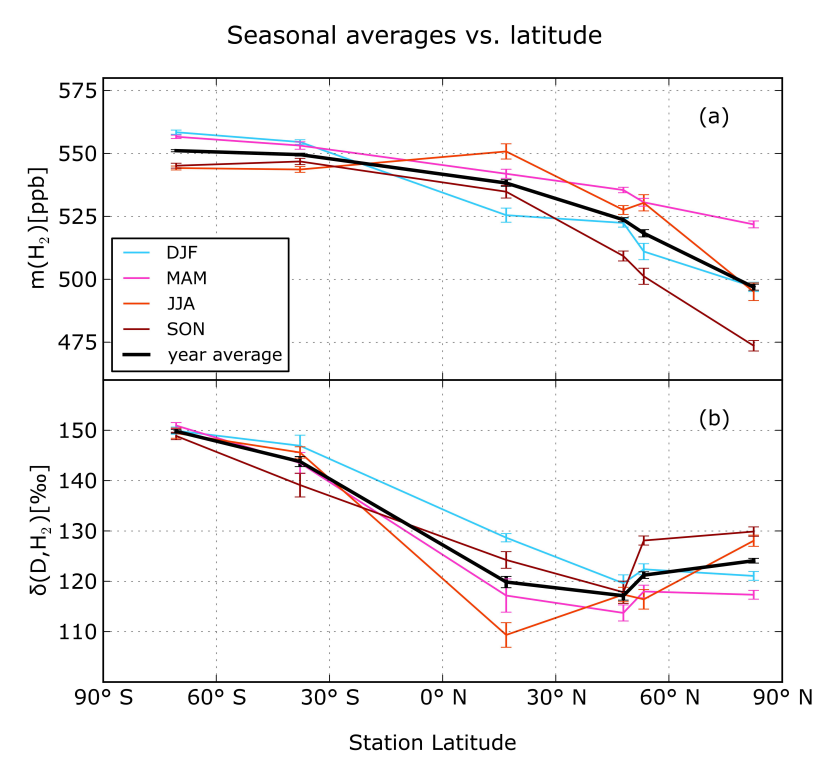

Fig. 4. Seasonal averages and seasonally weighted yearly averages of $m\left(\mathrm{H}_{2}\right)$ (a) and $\delta \mathrm{D}(\mathbf{b})$.

eliminates the scatter from analytical uncertainty and shortterm natural variability and allows the general shape of the seasonal cycles to be compared between the stations. The anticorrelated seasonal cycles of $\delta \mathrm{D}$ and $m\left(\mathrm{H}_{2}\right)$ at Alert can be seen very clearly. There is also an anticorrelation at Mace Head and Cape Verde, but the timing of the minima and maxima is different from the timing at Alert. Although it was not visible in the raw data in Fig. 2, the seasonal averages of the Schauinsland data seem to show a weak anticorrelation, which is primarily caused by the $\delta \mathrm{D}$ value having a minimum in spring, when $m\left(\mathrm{H}_{2}\right)$ shows a maximum. In comparison to the NH stations, the two SH stations have much smaller seasonal cycles in $m\left(\mathrm{H}_{2}\right)$ and $\delta \mathrm{D}$. The $\delta \mathrm{D}$ cycle at Neumayer does not seem well-correlated to the $\delta \mathrm{D}$ cycle at Amsterdam Island.

\subsection{Latitudinal gradients}

Figure 4 shows the latitudinal dependence of the seasonal averages. In all seasons, both mixing ratios and $\delta \mathrm{D}$ values are higher in the $\mathrm{SH}$ than in the $\mathrm{NH}$. The lowest average mixing ratios are found for the highest-latitude $\mathrm{NH}$ station (Alert) in all seasons. The minimum in $\delta \mathrm{D}$ is, however, not found at Alert for any season, but either at one of the midlatitude stations, or, in summer (JJA), at Cape Verde. As anthropogenic $\mathrm{H}_{2}$ emissions originate mainly from temperate latitudes (Hauglustaine and Ehhalt, 2002; Price et al., 2007), and $\mathrm{H}_{2}$ from anthropogenic source regions is usually depleted with respect to atmospheric $\mathrm{H}_{2}$, the midlatitude minimum can be attributed to anthropogenic influence. This is also evident in the spatial $\delta \mathrm{D}$ distribution modelled in TM5 (Pieterse et al., 2011).
Gerst and Quay (2000) concluded from their dataset, obtained from a Pacific Transect at the end of 1998 and two stations in North America, that there was a poleward decrease in $\delta \mathrm{D}$. However, at their northernmost sampling point (Point Barrow, $71^{\circ} \mathrm{N}$ ), the $\delta \mathrm{D}$ values seem to be exceptionally low. Whereas the rest of the data agree reasonably well with our measurements, their measurements from Point Barrow are more than $20 \%$ o lower than our data from Alert. The potential problems with these Point Barrow measurements have been discussed above. We note that without this sampling point, also the data from Gerst and Quay (2000) show a $\delta \mathrm{D}$ minimum at temperate northern latitudes.

From Fig. 4, it is clear that the latitudinal gradient varies with season. As the seasonal variation in both $m\left(\mathrm{H}_{2}\right)$ and $\delta \mathrm{D}$ is much larger in the $\mathrm{NH}$ than in the $\mathrm{SH}$, the size of the latitudinal gradient is for the largest part determined by the variation in the NH. Hence, the smallest pole-to-pole $\delta \mathrm{D}$ difference (19\%o between Neumayer and Alert) is found when $\delta \mathrm{D}$ is at its maximum in Alert, i.e., in SON. During this season, $m\left(\mathrm{H}_{2}\right)$ is lowest in Alert, and therefore the $m\left(\mathrm{H}_{2}\right)$ difference is largest (72 ppb). At that time, soil uptake in Alert is past its summer peak, so that $\mathrm{H}_{2}$ mixing ratios are low and the remaining $\mathrm{H}_{2}$ is isotopically enriched. Reversely, the largest $\delta \mathrm{D}$ pole-to-pole difference $(34 \%$ ) is found when $\delta \mathrm{D}$ is at its minimum in Alert and $m\left(\mathrm{H}_{2}\right)$ is at its maximum, namely in MAM, when over winter $\mathrm{H}_{2}$ from depleted sources has accumulated without being absorbed by the snow-covered soil. This is accompanied by the smallest difference in $m\left(\mathrm{H}_{2}\right)$ (35 ppb).

The interhemispheric difference reported by Gerst and Quay (2000) was about 15\%o, and Rice et al. (2010) found a similar gradient, $(16 \pm 12) \%$. The interpolar difference from the EUROHYDROS stations is clearly larger, but we miss a station at low southern latitudes to be able to make a reliable southern hemispheric average and to calculate a reliable difference between the two hemispheres.

\subsection{Latitude dependence of the apparent fractionation factor}

If it is assumed that the seasonal cycles of $\mathrm{H}_{2}$ and its isotopic composition are primarily determined by the sink processes, the fractionation factor $\alpha$, i.e., the ratio of the removal rate of the heavy isotope species $\left(k_{\mathrm{HD}}\right)$ to the removal rate of the light isotope species $\left(k_{\mathrm{HH}}\right)$, can be calculated from the time series as for a single stage Rayleigh fractionation process (see, Rhee et al., 2006b). In such a Rayleigh removal process, $m\left(\mathrm{H}_{2}\right)$ and $\delta \mathrm{D}$ evolve as

$(\alpha-1) \ln \left[\frac{m\left(\mathrm{H}_{2}\right)}{m\left(\mathrm{H}_{2}, \max \right)}\right]=\ln (\delta \mathrm{D}+1)+c$

where $m\left(\mathrm{H}_{2}, \max \right)$ is the maximum value for $m\left(\mathrm{H}_{2}\right)$ found in the series and $\mathrm{c}$ is a constant. The real situation at the measurement stations is more complex than this simple Rayleigh fractionation model, as will be discussed below. Still, an 
"apparent" fractionation factor was calculated for each station from the slope of a linear fit to the data in a Rayleigh fractionation plot (Fig. 5). This apparent fractionation factor does not quantify the inherent isotope fractionation in one single reaction, but is calculated from atmospheric data collected in a complex situation that involves more than one sink reaction, as well as other processes such as mixing, and we denote this apparent fractionation factor by $\alpha_{\text {app. }}$. To make the straight-line fits, a Weighted Total Least-Squares (WTLS) fitting algorithm (Krystek and Anton, 2007) was used. This algorithm takes errors in both the $\mathrm{x}$ - and the $\mathrm{y}$ direction into account. The squared correlation coefficient $\left(R^{2}\right)$ and the F-test $p$-value were calculated for each station in the same way as they would be calculated for an "ordinary" least-squares fit of a straight line. The fits to the Amsterdam Island and Neumayer data yielded $p$-values above 0.05 , suggesting a less than $95 \%$ significance of the correlation. The fit to the Schauinsland data did yield a $p$-value that was slightly smaller than 0.05 , but the $R^{2}$-value for this fit is very low, which indicates that only a very small part of the variation present in the dataset is described by the fit. This means that the simple Rayleigh fractionation model may not be adequate for evaluation of the time series from Schauinsland and the $\mathrm{SH}$. This is not surprising, considering that no clear isotope seasonal cycles were found for these stations.

Of course, the isotopic composition of the $\mathrm{H}_{2}$ at the measurement stations depends not only on the fractionation in the removal processes, but also on the isotopic composition of the sources that influence the sites and their variation over the year. Also the relative contribution of the two sink processes (atmospheric $\mathrm{OH}$ oxidation and uptake by soils) to the total sink could conceivably vary with season. In this light, it is illustrative to look at the phase diagrams $(\delta \mathrm{D}$ plotted against $\left.m\left(\mathrm{H}_{2}\right)\right)$ of the monthly means that can be constructed from the three stations that show clear cycles (Fig. 6). For Alert, it is clear that these points do not fall on a single straight fractionation line, but on the ellipse that is traced by the two harmonic functions that were fitted to the $m\left(\mathrm{H}_{2}\right)$ and $\delta \mathrm{D}$ time series. This shows that in the fractionation plots in Fig. 5, not all of the spread around the fractionation lines is random scatter; some of this spread is caused by the phase difference between the $m\left(\mathrm{H}_{2}\right)$ and $\delta \mathrm{D}$ seasonal cycles. The largest part of this phase difference is probably caused by seasonal variation in the sources and sinks.

Allan et al. (2001) described such phase ellipses for model results of methane mixing ratio and the carbon isotopic composition of methane $\left(\delta\left({ }^{13} \mathrm{C}, \mathrm{CH}_{4}\right)\right)$. In their simulations with only one source and one sink process, the monthly means fell on a straight line. This line broadened into an ellipse when different sources with different seasonal cycles were combined, with the largest broadening effect for the sources of which the isotopic signature differed the most from the isotopic signature of the mean source. However, the differing phases of the different sources did not appreciably affect the slope of the major axis of the ellipse: this slope depended robustly on the fractionation factor assumed for the sink, suggesting that even if the phase diagram shows a broadened ellipse, this slope can provide a good estimate of the fractionation in the sink. The ellipse major axis coincided largely with a relationship the authors termed the "KIE line" after the Kinetic Isotope Effect, which is described by:

$$
\Delta \delta\left({ }^{13} \mathrm{C}, \mathrm{CH}_{4}\right)=\epsilon\left(1+\delta_{0}\left({ }^{13} \mathrm{C}, \mathrm{CH}_{4}\right)\right) \frac{\Delta m\left(\mathrm{CH}_{4}\right)}{m_{0}\left(\mathrm{CH}_{4}\right)}
$$

with subscript zero indicating a mean value, $\Delta$ indicating the difference of a value from the mean, $m\left(\mathrm{CH}_{4}\right)$ indicating methane mixing ratio, and $\varepsilon=\alpha-1$.

In the case of $\mathrm{H}_{2}$, seasonal variation in the sources and sinks contributes to the ellipse eccentricity, but Rhee et al. (2006b) showed that as long as the $\mathrm{H}_{2}$ system is in isotopic equilibrium on an annual basis, the isotopic fractionation does not depend on seasonal changes in source emissions. Since there is no evidence for a tropospheric trend in either $m\left(\mathrm{H}_{2}\right)$ or $\delta \mathrm{D}$, it is reasonable to assume isotope equilibrium for the years over which the data presented here were collected.

A factor that could still affect the analysis is a seasonally varying contribution of the two main sinks. However, especially in Alert, any variations in the relative contributions of the two sinks over the year are expected to be small, because even if soil uptake and atmospheric $\mathrm{OH}$ oxidation do not follow the exact same seasonal pattern, their patterns are expected to share the main characteristics, with a minimum in winter, and a peak in summer. Hence, although the Rayleigh fractionation model does not represent the full complexity of reality at the stations, the apparent fractionation constants determined with this model provide a good estimate of the total sink fractionation.

For Alert, Mace Head and Cape Verde, KIE lines were calculated with the hydrogen $\alpha_{\text {app }}$ obtained for the different stations, as well as with the fractionation constants (Rhee et al., 2006b) for the two $\mathrm{H}_{2}$ sink processes and added to Fig. 6 . Clearly, for Alert and Mace Head the KIE line of the fit lies closest to the KIE line of soil uptake, whereas in Cape Verde it lies closest to atmospheric $\mathrm{OH}$ oxidation. For these three stations, $\alpha_{\text {app }}$ is plotted versus station latitude in Fig. 7a. The apparent fractionation factor can be interpreted as a combination of the fractionation factors of the main sink processes. For Alert and Mace Head, the $\alpha_{\text {app }}$ values $(0.905 \pm 0.008$ and $0.884 \pm 0.014$, respectively) are close to the fractionation factor assigned to soil uptake $(\alpha=0.943 \pm 0.007)$. Rhee et al. (2006b) also concluded from a similar analysis on a small set of upper tropospheric air samples that the seasonal cycle of $\mathrm{H}_{2}$ in the $\mathrm{NH}$ is largely driven by soil uptake. Closer to the equator, at Cape Verde, $\alpha_{\text {app }}(0.704 \pm 0.029)$ is lower and closer to the value for oxidation by $\mathrm{OH}(\alpha=0.58 \pm 0.07)$. This indicates that the relative importance of the uptake by soil with respect to the destruction by $\mathrm{OH}$ increases with latitude. 


\section{Fractionation plots per station}

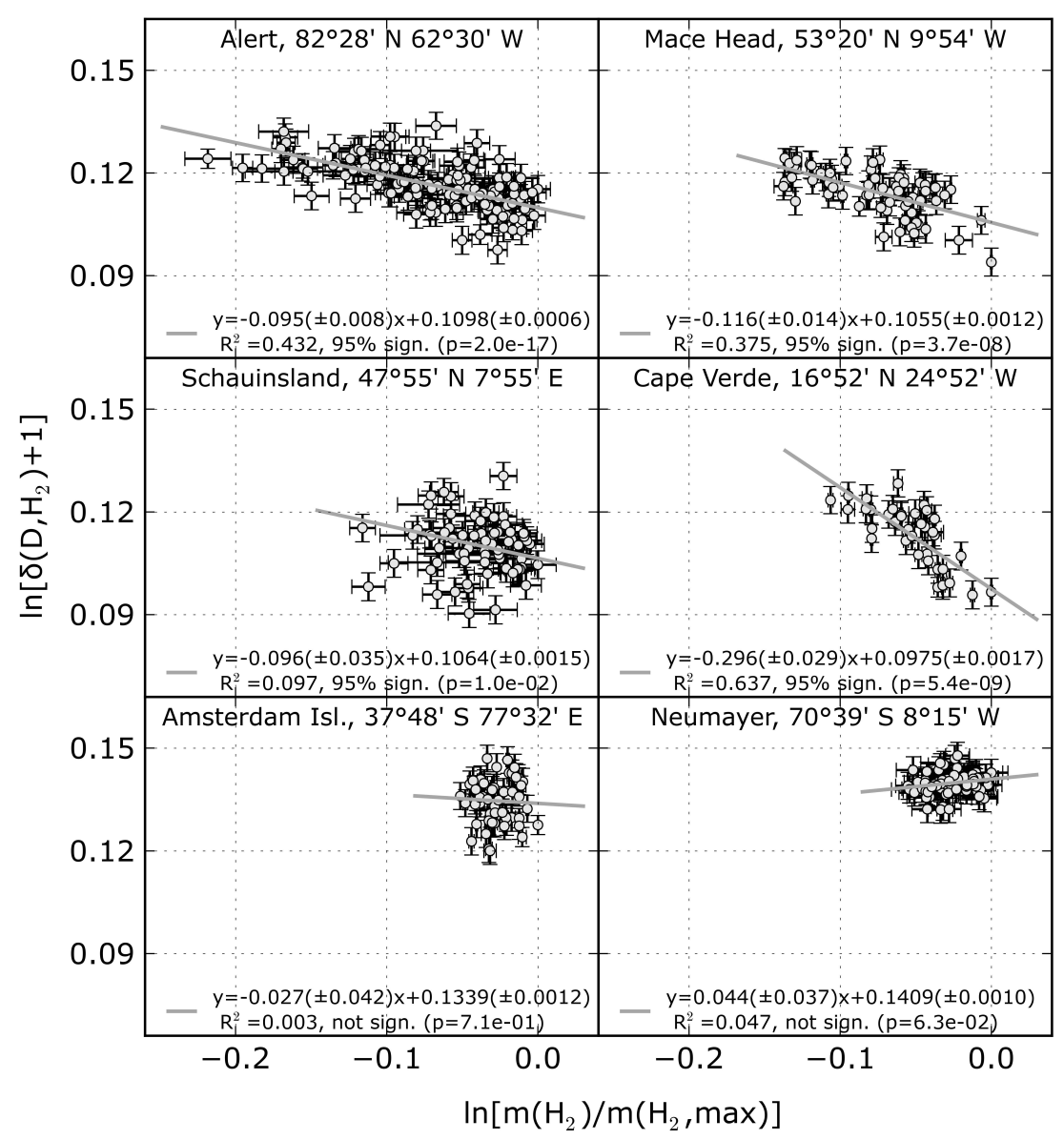

Fig. 5. Fractionation plots of the datasets from the different stations. Plotted $\operatorname{are} \ln (\delta \mathrm{D}+1)$ vs. $\ln \left(m\left(\mathrm{H}_{2}\right) / m\left(\mathrm{H}_{2}\right.\right.$, max $\left.)\right)$ with $m\left(\mathrm{H}_{2}\right.$, max $)$ the maximum mixing ratio found. Grey lines are the fitted lines obtained from the Weighted Total Least-Squares fitting routine. Error bars indicate one standard deviation. Indicated errors in the fit parameters indicate one standard error. $R^{2}$ is the squared correlation coefficient and $p$ is the $p$-value for the F statistic, both calculated as for an "ordinary" least squares fitted line.

Figure $7 \mathrm{~b}$ shows the relative contribution of both sinks processes to the total destruction of $\mathrm{H}_{2}$, as can be calculated from these isotope data if $\alpha_{\text {app }}$ is assumed to be a simple mass weighted average of the fractionation factors of soil removal and reaction with $\mathrm{OH}$. This calculation yields that $\mathrm{OH}$ destroys more than half $((66 \pm 15) \%)$ of the $\mathrm{H}_{2}$ at Cape Verde, but that at Alert, $\approx 90 \%$ of the $\mathrm{H}_{2}$ is destroyed by soil uptake. This finding of a latitudinal trend in the data presented here depends heavily on the Cape Verde station, where the formal application of the Rayleigh fractionation model yields a very low $\alpha_{\text {app }}$ and therefore a large contribution of $\mathrm{OH}$ oxidation to the total sinks. As discussed in Sect. 3.1.4, the $m\left(\mathrm{H}_{2}\right)$ and $\delta \mathrm{D}$ cycles at Cape Verde are shifted in time with respect to Alert and Mace Head, which indicates that the way the source, sink and transport processes drive the seasonal variations is somewhat different between these stations. But although $\alpha_{\text {app }}$ may be underestimated in Cape Verde, the gen- eral trend towards a higher $\mathrm{OH}$ fraction with decreasing latitude is in accordance with expectation and model results. In the TM5 model study, $\mathrm{H}_{2}$ destruction is clearly dominated by the soil sink in the high northern latitude band $\left(30^{\circ} \mathrm{N}-\right.$ $90^{\circ} \mathrm{N}$ ), whereas the two sinks are of comparable magnitude in the tropical latitude band $\left(30^{\circ} \mathrm{N}-30^{\circ} \mathrm{S}\right)$ (Fig. 8 in Pieterse et al., 2011). Therefore, our findings indicate that the $\mathrm{NH}$ average $\alpha_{\text {app }}$ of $0.90 \pm 0.02$ found by Rhee et al. (2006b) for a limited number of samples in the tropopause region and the associated $(87 \pm 7) \%$ relative contribution of the soil sink may be overestimates. This also means that their $\mathrm{H}_{2}$ lifetime estimate of $(1.4 \pm 0.2)$ years may be too short. To investigate this further, it would be useful to analyse samples from subtropical northern latitudes, for example the Iberian Peninsula, the Canary Islands or Morocco. 


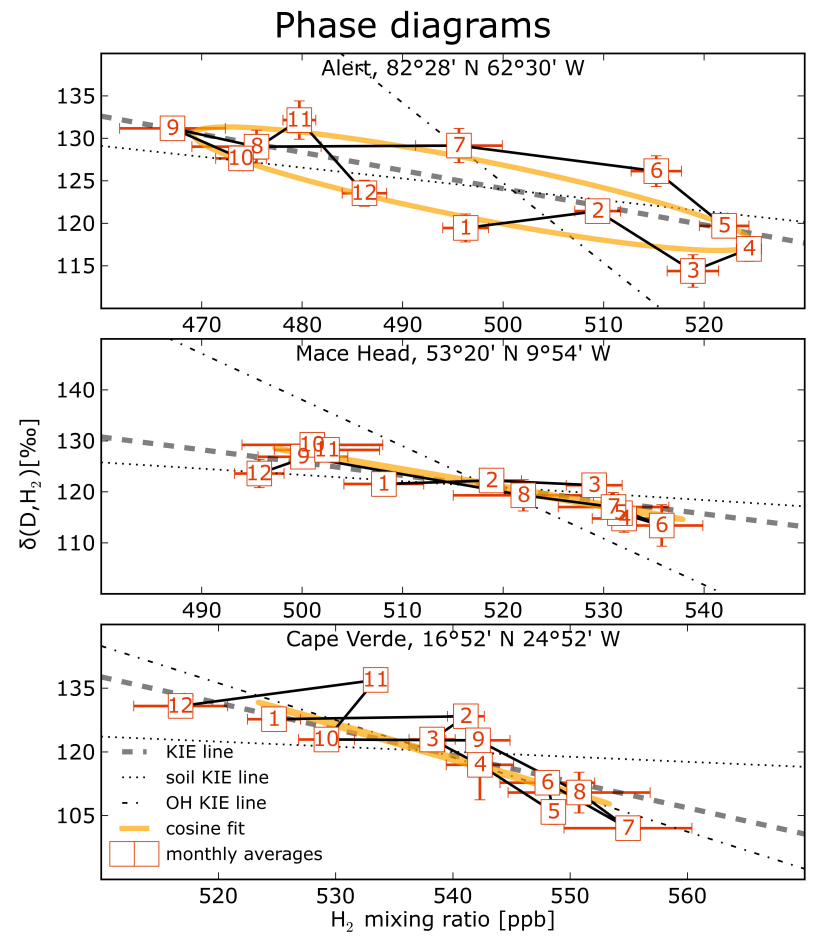

Fig. 6. Phase diagrams ( $\delta \mathrm{D}$ vs. $\left.m\left(\mathrm{H}_{2}\right)\right)$ of the monthly averages (labelled with month number) of the three stations that show clear seasonal cycles. The orange ellipses are derived from the sinusoidal fits to the time series. The thick grey dashed line is the "KIE" line for the apparent fractionation factor determined from the fractionation plot for the respective station as defined in (Allan et al., 2001). The dotted and dash-dotted lines are the KIE lines for the two different sink processes, with values for $\alpha$ from (Rhee et al., 2006b). Note that the determined KIE line at Alert and Mace Head is closest to the soil uptake KIE line, while the determined KIE line at Cape Verde is closer to the $\mathrm{OH}$ oxidation KIE line.

\section{Conclusions}

Air samples from six EUROHYDROS stations have been analysed regularly for $m\left(\mathrm{H}_{2}\right)$ and $\delta \mathrm{D}$, which allows analysis of the temporal and latitudinal distribution of $\mathrm{H}_{2}$ and its isotopic composition. These data greatly expand the existing $\delta \mathrm{D}$ dataset, and can be used to constrain the global and regional $\mathrm{H}_{2}$ budgets with the help of global and regional models.

The out-of-phase behaviour of $m\left(\mathrm{H}_{2}\right)$ and $\delta \mathrm{D}$ that was proposed for the NH (Rhee et al., 2006b) is seen at Mace Head and Cape Verde, and particularly clearly at Alert, but not at Schauinsland, which is a continental station and closer to anthropogenic source regions. The SH stations show very little variation in $\delta \mathrm{D}$, even when $m\left(\mathrm{H}_{2}\right)$ exhibits a small seasonal cycle. The $\delta \mathrm{D}$ data show a clear latitudinal gradient with higher values in the $\mathrm{SH}$ than in the $\mathrm{NH}$. This gradient varies with season, mainly driven by the seasonality in the NH. The observed pole-to-pole differences are larger than observed on ship cruises (Gerst and Quay, 2000; Rice et al., 2010). The
Fractionation on the Northern Hemisphere

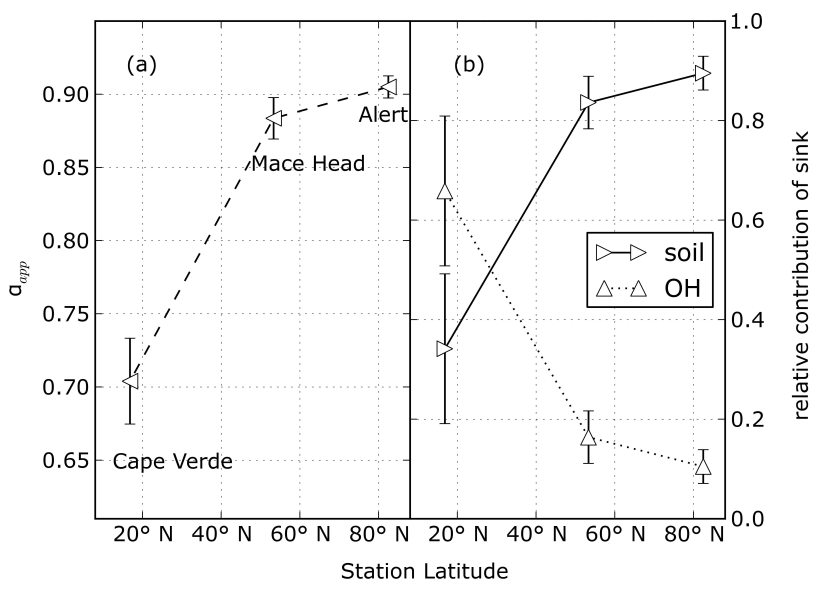

Fig. 7. (a) Apparent fractionation factors for the NH, calculated from a least-squares fit to a Rayleigh plot, plotted as a function of station latitude. (b) Relative contributions of uptake by soils and atmospheric oxidation by $\mathrm{OH}$ to the total sinks, calculated from the apparent fractionation factors and the values for the fractionation processes used by Rhee et al. (2006b). Error bars indicate one standard error.

lowest annual average $\delta \mathrm{D}$ value is not found at the highest NH latitude station, but at lower NH latitudes, where the influence of the anthropogenic fossil fuel combustion source is strongest. If it is assumed that the seasonality of the $m\left(\mathrm{H}_{2}\right)$ and $\delta \mathrm{D}$ time series is mainly determined by the removal processes, the relative changes of $m\left(\mathrm{H}_{2}\right)$ and $\delta \mathrm{D}$ can be used to provide information on the relative sink strengths of soil deposition and atmospheric oxidation. The data then indicate that at high NH latitudes, the removal processes are almost completely dominated by deposition to soil, whereas in the tropics, soil deposition and atmospheric oxidation by $\mathrm{OH}$ are of similar importance. Our findings imply that the previously reported average value of $\alpha_{\text {app }}$ for the $\mathrm{NH}$ and the large relative contribution of the soil sink derived from it may be overestimates.

Acknowledgements. This project was part of the EUROHYDROS project, funded via the Sixth Framework Programme of the European Union (SUSTDEV-2005-3.I.2.1 Atmospheric composition change: Methane, Nitrous Oxide and Hydrogen). We also acknowledge support from the Dutch NWO-ACTS project 053.61.026.

For the trajectory study of the Mace Head data we used the NOAA Air Resources Laboratory (ARL) Hybrid Single Particle Lagrangian Integrated Trajectory Model (HYSPLIT): http://www.arl.noaa.gov/HYSPLIT_info.php. Graphics for this article were generated using Python 2.6 with the matplotlib and pylab packages.

Edited by: J. Kaiser 


\section{References}

Allan, W., Manning, M., Lassey, K., Lowe, D., and Gomez, A.: Modeling the variation of $\delta^{13} \mathrm{C}$ in atmospheric methane: Phase ellipses and the kinetic isotope effect, Glob. Biochem. Cy., 15(2), 467-481, doi:10.1029/2000GB001281, 2001.

Bousquet, P., Yver, C., Pison, I., Li, Y. S., Fortems, A., Hauglustaine, D., Szopa, S., Rayner, P. J., Novelli, P., Langenfelds, R., Steele, P., Ramonet, M., Schmidt, M., Foster, P., Morfopoulos, C., and Ciais, P.: A three-dimensional synthesis inversion of the molecular hydrogen cycle: Sources and sinks budget and implications for the soil uptake, J. Geophys. Res., 116, doi:10.1029/2010JD014599, 2011.

De Wit, J. C., Van der Straten, C. M., and Mook, W. G.: Determination of the absolute isotopic ratio of V-SMOW and SLAP, Geostandards Newsletter, 4, 33-36, doi:10.1111/j.1751908X.1980.tb00270.x, 1980.

Ehhalt, D. H.: Tritium and deuterium in atmospheric hydrogen, Tellus, 18(2-3), 249-255, doi:10.1111/j.21533490.1966.tb00233.x, 1966.

Ehhalt, D. H. and Rohrer, F.: The tropospheric cycle of $\mathrm{H}_{2}$ : a critical review, Tellus B, 61(3), 500-535, doi:10.1111/j.16000889.2009.00416.x, 2009.

Ehhalt, D. H., Schmidt, U., and Heidt, L. E.: Vertical Profiles of Molecular Hydrogen in the Troposphere and Stratosphere, J. Geophys. Res., 82(37), 5907-5911, doi:10.1029/JC082i037p05907, 1977.

Engel, A.: EUROHYDROS, A European Network for Atmospheric Hydrogen Observations and studies: Final Report, available on request from A. Engel (an.engel@iau.uni-frankfurt.de), 2009.

Feck, T., Grooß, J.-U., and Riese, M.: Sensitivity of Arctic ozone loss to stratospheric $\mathrm{H}_{2} \mathrm{O}$, Geophys. Res. Lett., 35(1), 1-20, doi:10.1029/2007GL031334, 2008.

Feilberg, K. L., Johnson, M. S., Bacak, A., Röckmann, T., and Nielsen, C.: J. Relative tropospheric photolysis rates of HCHO and HCDO measured at the European Photoreactor Facility., J. Phys. Chem. A, 111(37), 9034-9046, doi:10.1021/jp070185x, 2007.

Gerst, S. and Quay, P.: The deuterium content of atmospheric molecular hydrogen: Method and initial measurements, J. Geophys. Res., 105, 26433-26445, doi:10.1029/2000JD900387, 2000.

Gerst, S. and Quay, P.: Deuterium component of the global molecular hydrogen cycle, J. Geophys. Res., 106, 5021-5031, doi:10.1029/2000JD900593, 2001.

Glueckauf, E. and Kitt, G. P.: The hydrogen content of atmospheric air at ground level, Q. J. Roy. Meteorol. Soc., 83(358), 522-528, doi:10.1002/qj.49708335808, 1957.

Gonfiantini, R., Stichler, W., and Rozanski, K.: Standards and intercomparison materials distributed by the International Atomic Energy Agency for stable isotope measurements, in: Reference and intercomparison materials for stable isotopes of light elements: Proceedings of a consultants meeting held in Vienna, 1-3 December 1993, IAEA-TECDOC-825, International Atomic Energy Agency, 1993.

Grant, A., Witham, C. S., Simmonds, P. G., Manning, A. J., and O'Doherty, S.: A 15 year record of high-frequency, in situ measurements of hydrogen at Mace Head, Ireland, Atmos. Chem. Phys., 10, 1203-1214, doi:10.5194/acp-10-1203-2010, 2010.

Hammer, S. and Levin, I.: Seasonal variation of the molecular hy- drogen uptake by soils inferred from continuous atmospheric observations in Heidelberg, southwest Germany, Tellus B, 61(3), 556-565, doi:10.1111/j.1600-0889.2009.00417.x, 2009.

Hauglustaine, D. A. and Ehhalt, D. H.: A three-dimensional model of molecular hydrogen in the troposphere, J. Geophys. Res., 107, 4330, doi:10.1029/2001JD001156, 2002.

Jordan, A. and Steinberg, B.: Calibration of atmospheric hydrogen measurements, Atmos. Meas. Tech., 4, 509-521, doi:10.5194/amt-4-509-2011, 2011.

Krystek, M. and Anton, M.: A weighted total least-squares algorithm for fitting a straight line, Meas. Sci. Technol., 18(11), 3438-3442, doi:10.1088/0957-0233/18/11/025, 2007.

Mar, K. A., McCarthy, M. C., Connell, P., and Boering, K. A.: Modeling the photochemical origins of the extreme deuterium enrichment in stratospheric $\mathrm{H}_{2}$, J. Geophys. Res, 112, D19302, doi:10.1029/2006JD007403, 2007.

Nilsson, E. J. K., Johnson, M. S., Taketani, F., Matsumi, Y., Hurley, M. D., and Wallington, T. J.: Atmospheric deuterium fractionation: $\mathrm{HCHO}$ and $\mathrm{HCDO}$ yields in the $\mathrm{CH}_{2} \mathrm{DO}+\mathrm{O}_{2}$ reaction, Atmos. Chem. Phys., 7, 5873-5881, doi:10.5194/acp-7-5873-2007, 2007.

Novelli, P. C., Lang, P. M., Masarie, K. A., Hurst, D. F., Myers, R., and Elkins, J. W.: Molecular hydrogen in the troposphere: Global distribution and budget, J. Geophys. Res., 104, 3042730444, doi:10.1029/1999JD900788, 1999.

Pieterse, G., Krol, M. C., and Röckmann, T.: A consistent molecular hydrogen isotope chemistry scheme based on an independent bond approximation, Atmos. Chem. Phys., 9, 8503-8529, doi:10.5194/acp-9-8503-2009, 2009.

Pieterse, G., Krol, M. C., Batenburg, A. M., Steele, L. P., Krummel, P. B., Langenfelds, R. L., and Röckmann, T.: Global modelling of $\mathrm{H}_{2}$ mixing ratios and isotopic compositions with the TM5 model, Atmos. Chem. Phys., 11, 7001-7026, doi:10.5194/acp11-7001-2011, 2011.

Price, H., Jaeglé, L., Rice, A., Quay, P., Novelli, P. C., and Gammon, R.: Global budget of molecular hydrogen and its deuterium content: Constraints from ground station, cruise, and aircraft observations, J. Geophys. Res., 112(D22), 1-16, doi:10.1029/2006JD008152, 2007.

Rahn, T., Eiler, J. M., Kitchen, N., Fessenden, J. E., and Randerson, J. T.: Concentration and $\delta \mathrm{D}$ of molecular hydrogen in boreal forests: Ecosystem-scale systematics of atmospheric $\mathrm{H}_{2}$, Geophys. Res. Lett., 29(18), 1888, doi:10.1029/2002GL015118, 2002a.

Rahn, T., Kitchen, N., and Eiler, J.: D/H ratios of atmospheric $\mathrm{H}_{2}$ in urban air: results using new methods for analysis of nanomolar $\mathrm{H}_{2}$ samples, Geochim. Cosmochim. Ac., 66(14), 24752481, doi:10.1016/S0016-7037(02)00858-X, 2002b.

Rahn, T., Eiler, J. M., Boering, K. A., Wennberg, P. O., McCarthy, M. C., Tyler, S., Schauffler, S., Donnelly, S., and Atlas, E.: Extreme deuterium enrichment in stratospheric hydrogen and the global atmospheric budget of $\mathrm{H}_{2}$, Nature, 424, 918-921, doi:10.1038/nature01917, 2003.

Rhee, T. S., Mak, J., Röckmann, T., and Brenninkmeijer, C. A. M.: Continuous-flow isotope analysis of the deuterium/hydrogen ratio in atmospheric hydrogen, Rapid Commun. Mass Spectrom., 18(3), 299-306, doi:10.1002/rcm.1309, 2004.

Rhee, T. S., Brenninkmeijer, C. A. M., Brass, M., and Brühl, C.: Isotopic composition of $\mathrm{H}_{2}$ from $\mathrm{CH}_{4}$ oxidation in the 
stratosphere and the troposphere, J. Geophys. Res., 111(D23), D23303, doi:10.1029/2005JD006760, 2006a.

Rhee, T. S., Brenninkmeijer, C. A. M., and Röckmann, T.: The overwhelming role of soils in the global atmospheric hydrogen cycle, Atmos. Chem. Phys., 6, 1611-1625, doi:10.5194/acp-61611-2006, 2006b.

Rhee, T. S., Brenninkmeijer, C. A. M., and Röckmann, T.: Hydrogen isotope fractionation in the photolysis of formaldehyde, Atmos. Chem. Phys., 8, 1353-1366, doi:10.5194/acp-8-1353-2008, 2008.

Rice, A., Quay, P., Stutsman, J., Gammon, R., Price, H., and Jaeglé, L.: Meridional distribution of molecular hydrogen and its deuterium content in the atmosphere, J. Geophys. Res., 115(D12), 1-12, doi:10.1029/2009JD012529, 2010.

Rice, A., Dayalu, A., Quay, P., and Gammon, R.: Isotopic fractionation during soil uptake of atmospheric hydrogen, Biogeosciences, 8, 763-769, doi:10.5194/bg-8-763-2011, 2011.

Röckmann, T., Rhee, T. S., and Engel, A.: Heavy hydrogen in the stratosphere, Atmos. Chem. Phys., 3, 2015-2023, doi:10.5194/acp-3-2015-2003, 2003.

Röckmann, T., Álvarez, C. X. G., Walter, S., Veen, C. van der, Wollny, A. G., Gunthe, S. S., Helas, G., Pöschl, U., Keppler, F., Greule, M., and Brand, W. A.: Isotopic composition of $\mathrm{H}_{2}$ from wood burning: Dependency on combustion efficiency, moisture content, and $\delta \mathrm{D}$ of local precipitation, J. Geophys. Res., 115, D17308, doi:201010.1029/2009JD013188, 2010a.

Röckmann, T., Walter, S., Bohn, B., Wegener, R., Spahn, H., Brauers, T., Tillmann, R., Schlosser, E., Koppmann, R., and Rohrer, F.: Isotope effect in the formation of $\mathrm{H}_{2}$ from $\mathrm{H}_{2} \mathrm{CO}$ studied at the atmospheric simulation chamber SAPHIR, Atmos. Chem. Phys., 10, 5343-5357, doi:10.5194/acp-10-5343-2010, 2010b.

Rothe, M., Jordan, A., and Brand, W. A.: Trace gases, $\delta^{13} \mathrm{C}$ and $\delta^{18} \mathrm{O}$ of $\mathrm{CO}_{2}$-in-air samples: Storage in glass flasks using PCTFE seals and other effects, in: GAW report $161,12^{\text {th }}$ WMO/IAEA meeting of experts on carbon dioxide concentration and related tracers measurements techniques, edited by: Worthy, D. and Huang, L., Toronto, Canada, 15-18 September 2003, WMO TD No. 1275, 2004.

Sanderson, M. G., Collins, W. J., Derwent, R. G., and Johnson, C. E.: Simulation of global hydrogen levels using a Lagrangian three-dimensional model, J. Atmos. Chem., 46, 15-28, doi:10.1023/a:1024824223232, 2003.

Schmidt, M., Graul, R., Sartorius, H., and Levin, I.: Carbon dioxide and methane in continental Europe: a climatology, and ${ }^{222}$ Radon-based emission estimates, Tellus B, 48(4), 457-473, doi:10.1034/j.1600-0889.1994.t01-2-00002.x-i1, 1996.

Schmidt, U.: Molecular hydrogen in the atmosphere, Tellus, 26(12), 78-90, doi:10.1111/j.2153-3490.1974.tb01954.x, 1974.

Schmidt, U. and Seiler, W.: A New Method for Recording Molecular Hydrogen in Atmospheric Air, J. Geophys. Res., 75(9), 17131716, doi:197010.1029/JC075i009p01713, 1970.
Schultz, M. G., Diehl, T., Brasseur, G. P., and Zittel, W.: Air pollution and climate-forcing impacts of a global hydrogen economy, Science, 302(5645), 624-627, doi:10.1126/science.1089527, 2003.

Tromp, T. K., Shia, R.-L., Allen, M., Eiler, J. M., and Yung, Y. L.: Potential Environmental Impact of a Hydrogen Economy on the Stratosphere, Science, 300, 1740-1742, doi:10.1126/science.1085169, 2003.

Vollmer, M. K., Walter, S., Bond, S. W., Soltic, P., and Röckmann, T.: Molecular hydrogen $\left(\mathrm{H}_{2}\right)$ emissions and their isotopic signatures (H/D) from a motor vehicle: implications on atmospheric $\mathrm{H}_{2}$, Atmos. Chem. Phys., 10, 5707-5718, doi:10.5194/acp-105707-2010, 2010.

Warwick, N. J., Bekki, S., Nisbet, E. G., and Pyle, J. A.: Impact of a hydrogen economy on the stratosphere and troposphere studied in a 2-D model, Geophys. Res. Lett., 31(5), 2-5, doi:10.1029/2003GL019224, 2004.

Yashiro, H., Sudo, K., Yonemura, S., and Takigawa, M.: The impact of soil uptake on the global distribution of molecular hydrogen: chemical transport model simulation, Atmos. Chem. Phys. Discuss., 11, 4059-4103, doi:10.5194/acpd-11-4059-2011, 2011.

Yver, C.: Estimation des sources et puits du dihydrogène troposphérique: développements instrumentaux, mesures atmosphériques et assimilation variationnelle. Ph.D. thesis, University of Versailles, Saint Quentin, France, http://www.sudoc.abes. $\mathrm{fr} / \mathrm{xslt} / \mathrm{DB}=2.1 / \mathrm{SET}=1 / \mathrm{TTL}=1 / \mathrm{SHW}$ ?FRST=2, 2010.

Yver, C., Schmidt, M., Bousquet, P., Zahorowski, W., and Ramonet, M.: Estimation of the molecular hydrogen soil uptake and traffic emissions at a suburban site near Paris through hydrogen, carbon monoxide, and radon-222 semicontinuous measurements, J. Geophys. Res., 114(D18), 1-12, doi:10.1029/2009JD012122, 2009.

Yver, C. E., Pison, I. C., Fortems-Cheiney, A., Schmidt, M., Chevallier, F., Ramonet, M., Jordan, A., Søvde, O. A., Engel, A., Fisher, R. E., Lowry, D., Nisbet, E. G., Levin, I., Hammer, S., Necki, J., Bartyzel, J., Reimann, S., Vollmer, M. K., Steinbacher, M., Aalto, T., Maione, M., Arduini, J., O’Doherty, S., Grant, A., Sturges, W. T., Forster, G. L., Lunder, C. R., Privalov, V., Paramonova, N., Werner, A., and Bousquet, P.: A new estimation of the recent tropospheric molecular hydrogen budget using atmospheric observations and variational inversion, Atmos. Chem. Phys., 11, 3375-3392, doi:10.5194/acp-11-3375-2011, 2011.

Xiao, X., Prinn, R. G., Simmonds, P. G., Steele, L. P., Novelli, P. C., Huang, J., Langenfelds, R. L., O’Doherty, S., Krummel, P. B., Fraser, P. J., Porter, L. W., Weiss, R. F., Salameh, P., and Wange, R. H. J.: Optimal estimation of the soil uptake rate of molecular hydrogen from the Advanced Global Atmospheric Gases Experiment and other measurements, J. Geophys. Res., 112, D07303, doi:10.1029/2006JD007241, 2007. 